\title{
A PEDAGOGIA TECNICISTA: UM BREVE PANORAMA
}

\begin{abstract}
Abimael Antunes Marques. Professor do Instituto Federal de Educação, Ciência e Tecnologia do Mato Grosso, IFMT, Campus São Vicente e doutorando do Programa de PósGraduação em Educação da Universidade Federal de Uberlândia-MG, Linha de Pesquisa História e Historiografia da Educação. E-mail: abimael1958@ gmail.com
\end{abstract}

RESUMO: O presente trabalho faz, primeiramente, uma pequena e simbólica explanação a respeito das principais tendências pedagógicas ocorridas no Brasil dos anos novecentos e que, certamente, ainda se encontram presentes nos dias atuais. Mais adiante, se aprofunda na Pedagogia Tecnicista sob a ótica de Acácia Zeneida Kuenzer e Lucília Regina de Souza Machado.

Palavras-chave: Educação Profissional e Tecnológica. Tecnologia Tecnicismo

ABSTRACT: The present study is, first, a small and symbolic explanation as the main pedagogical trends that occurred in Brazil in the year nine hundred and, indeed, are still present today. Later in deepens Technicist Pedagogy from the perspective of Acacia Zeneida Kuenzer and Lucilia Regina de Souza Machado.

Keywords: Vocational and Technological Education. Technology. technicality

\section{INTRODUÇÃO}

O tema do presente artigo é a Pedagogia Tecnicista, porém antes de nos dedicarmos ao objeto maior desse artigo, entendemos ser necessário, para melhor compreensão dos nossos interlocutores e até mesmo por uma questão de didática, apresentar uma breve ilustração sobre as principais tendências pedagógicas em evidência desde o início do Brasil republicano para em seguida apresentar a pedagogia tecnicista, desde sua origem histórica até sua caracterização na prática escolar. 
Embora se reconheçam as dificuldades do estabelecimento de uma síntese dessas diferentes tendências pedagógicas, cujas influências se refletem no ecletismo do ensino atual, procuraremos apresentar, neste primeiro momento, a teoria de José Carlos Libâneo, que as classifica em dois grupos distintos: tendências pedagógicas liberais e tendências pedagógicas progressistas. No primeiro grupo, estão incluídas a tendência tradicional, a tendência renovada progressivista, a tendência renovada não-diretiva e a tendência tecnicista. No segundo grupo estão inseridas a tendência libertadora, a tendência libertária e a tendência crítico-social dos conteúdos.

\subsection{TENDÊNCIAS PEDAGÓGICAS LIBERAIS}

Segundo LIBÂNEO (1990), a pedagogia liberal traz em seu bojo a idéia de que a escola tem por finalidade precípua educar os indivíduos para o desempenho de papéis sociais, de acordo com as aptidões individuais. Isso nos faz acreditar que o indivíduo precisa adequarse às normas e valores vigentes na sociedade de classe, através do desenvolvimento da cultura individual. Quando se dá ênfase ao aspecto cultural, as diferenças entre as classes sociais deixam de ser consideradas, pois, embora a escola passe a difundir a idéia de igualdade de oportunidades, não leva em conta a desigualdade de condições.

Esta é, portanto a concepção filosófica e epistemológica que predomina no âmbito das sociedades marcadas por uma estrutura social capitalista na qual a função da escola e, do ensino em particular concentra-se em reproduzir a ideologia dominante.

\subsubsection{TENDÊNCIA LIBERAL TRADICIONAL}

De acordo com esse quadro teórico, a tendência liberal tradicional é caracterizada por dar ênfase ao ensino humanístico, de cultura geral. Segundo essa escola tradicional, o estudante é preparado para atingir sua plenitude através de seu próprio esforço. Dessa forma, as diferenças de classe social não são consideradas e toda a prática escolar não tem nenhuma relação com o cotidiano do aluno. Cabe ao professor conduzir o processo e ao aluno receptivo, apenas memorizar o que foi passado para ele.

\subsubsection{TENDÊNCIA LIBERAL RENOVADA PROGRESSIVISTA}


De acordo com essa perspectiva teórica de Libâneo, a tendência liberal renovada progressivista, também conhecida como pragmatista - Escola Nova enfatiza o sentido da cultura como pressuposto para o desenvolvimento das aptidões individuais. A escola continua desse modo, a preparar o educando para que o mesmo possa desempenhar seu papel na sociedade, adaptando as necessidades do aluno ao meio social, por isso ela deve imitar a vida.

Se, na tendência liberal tradicional, a atividade pedagógica estava centrada no professor, na escola renovada progressivista, defende-se a idéia de "aprender fazendo", portanto centrada no educando, valorizando as tentativas experimentais, a pesquisa, a descoberta, o estudo do meio natural e social, etc., levando em conta os interesses do aluno. Surge nessa concepção a importância da Psicologia para justificar tanto o sucesso escolar como o fracasso do aluno.

\subsubsection{TENDÊNCIA LIBERAL RENOVADA NÃO-DIRETIVA}

Acentua-se, nessa tendência, o papel da escola na formação de atitudes, razão pela qual deve estar mais preocupada com os problemas psicológicos do que com os pedagógicos ou sociais. Todo o esforço deve ser direcionado para proporcionar a uma mudança no interior do indivíduo, ou seja, a uma adaptação pessoal às solicitações do ambiente. Aprender é modificar suas próprias percepções. Apenas se aprende o que estiver significativamente relacionado com essas percepções. A retenção se dá pela relevância do aprendido em relação ao "eu", o que torna a avaliação escolar sem sentido, proporcionando privilégios à autoavaliação. Trata-se de um ensino centrado no aluno, sendo o professor apenas um facilitador.

\subsubsection{TENDÊNCIA LIBERAL TECNICISTA}

Ainda no âmbito da tendência liberal tradicional encontramos a escola liberal tecnicista que atua no aperfeiçoamento da ordem social vigente (o sistema capitalista), articulando-se diretamente com o sistema produtivo; para tanto, emprega a ciência da mudança de comportamento, ou seja, a tecnologia comportamental. Seu interesse principal é, portanto, produzir indivíduos "competentes" para o mercado de trabalho, não se preocupando 
com as mudanças sociais. À frente, nos dedicaremos de forma mais aprofundada a essa tendência, objeto maior desse artigo.

\subsection{TENDÊNCIAS PEDAGÓGICAS PROGRESSISTAS}

Segundo LIBÂNEO (1990), a pedagogia progressista designa as tendências que, partindo de uma análise crítica da realidade social, sustentam implicitamente as finalidades sociopolíticas da educação.

\subsubsection{TENDÊNCIA PROGRESSISTA LIBERTADORA}

As tendências progressistas libertadora e libertária têm em comum, a defesa da autogestão pedagógica e o antiautoritarismo. A escola libertadora, também conhecida como a pedagogia de Paulo Freire, vincula a educação à luta e à organização de classe do oprimido.

De acordo com GADOTTI (1988), Paulo Freire não considera o papel informativo, o ato de conhecimento na relação educativa, mas insiste que o conhecimento não é suficiente se, ao lado e junto deste, não se elabora uma nova teoria do conhecimento e se os oprimidos não podem adquirir uma nova estrutura do conhecimento que lhes permita reelaborar e reordenar seus próprios conhecimentos e apropriar-se de outros.

Assim, para Paulo Freire, no contexto da luta de classes, o saber mais importante para o oprimido é a descoberta da sua situação de oprimido, a condição para se libertar da exploração política e econômica, através da elaboração da consciência crítica passo a passo com sua organização de classe. Por isso, a pedagogia libertadora ultrapassa os limites da pedagogia, situando-se também no campo da economia, da política e das ciências sociais, segundo Gadotti.

\subsubsection{TENDÊNCIA PROGRESSISTA LIBERTÁRIA}

A escola progressista libertária parte do pressuposto de que somente o vivenciado pelo aluno pode ser incorporado e utilizado em situações novas, por isso o saber sistematizado só terá relevância se for possível seu uso prático. A ênfase na aprendizagem informal, assimilada através de grupo, e a negação de toda forma de repressão, visam a favorecer o desenvolvimento de pessoas mais livres. 


\subsubsection{TENDÊNCIA PROGRESSISTA CRÍTICO-SOCIAL DOS CONTEÚDOS}

Conforme LIBÂNEO (1990), a tendência progressista crítico-social dos conteúdos, diferentemente das tendências libertadora e libertária, enfatiza a primazia dos conteúdos no seu confronto com as realidades sociais. A atuação da escola consiste na preparação do educando para o mundo adulto e suas contradições, fornecendo-lhe um instrumental, por meio da aquisição de conteúdos e da socialização, para uma participação organizada e ativa na democratização da sociedade. Na visão da pedagogia dos conteúdos, admite-se o princípio da aprendizagem significativa, partindo do que o aluno já sabe. A transferência da aprendizagem só se realiza no momento da síntese, isto é, quando o aluno supera sua visão parcial e confusa e adquire uma visão mais clara e unificadora.

Com base no quadro teórico proposto por José Carlos Libâneo, podemos deduzir que as tendências pedagógicas liberais, ou seja, a tradicional, a renovada e a tecnicista, por se declararem neutras, jamais assumiram compromisso com as transformações da sociedade e na prática, procuram legitimar a ordem econômica e social do sistema capitalista. Já as tendências pedagógicas progressistas, em oposição às liberais, têm em comum a análise crítica do sistema capitalista.

\section{A PEDAGOGIA TECNICISTA}

\subsection{Considerações iniciais}

Após essa breve contextualização a respeito das principais tendências pedagógicas voltaremos nosso olhar sobre a Pedagogia Tecnicista.

Problematizar e investigar a respeito das concepções da Pedagogia Tecnicista no Brasil, ocorrida nos anos 1960-1979, - esse período é questionável -, sob a ótica de Acácia Zeneida Kuenzer e Lucília Regina de Souza Machado (1986), nos levará a refletir um pouco mais sobre essa teoria que tão massacrada foi pelos estudiosos da educação.

Em artigo publicado em 1986, Acácia Zeneida Kuenzer e Lucília Regina de Souza Machado, são enfáticas ao afirmar que essa pedagogia foi implantada no Brasil para atender aos interesses do capital estrangeiro, principalmente o americano, através da necessidade de 
preparação de uma mão-de-obra que pudesse atender à demanda das multinacionais que invadiam a nação brasileira.

Ainda, segundo as autoras, essa tecnologia educacional surgiu como alternativa estatal para se fazer a educação popular, em outras palavras, essa tecnologia deveria absorver a ideologia empresarial vigente para produzir um produto escolar adequado (Kuenzer e Machado, 1986, p. 30).

Colocada neste contexto, essa pedagogia só pode ser entendida a partir do momento em que se insere no processo produtivo. O processo produtivo só se sistematizou em fins do século XIX e início do século XX, através da criação da Teoria Geral de Administração, cujo representante e mais importante teórico foi Frederick W. Taylor, cujas idéias permanecem entre nós até os dias atuais. A Teoria Geral de Administração surgiu para sistematizar a organização do trabalho e fazer o seu controle.

\subsection{A Teoria Geral de Administração}

A Teoria Geral de Administração surge tendo como objetivo principal o controle do processo produtivo, pois assim necessitava o desenvolvimento gerado pelo capitalismo, que introduzia novas relações de produção com o trabalhador, através da compra e venda da força de trabalho. Assim, surge a figura do gerente, que passa a fazer o planejamento e controle dos processos, antes realizados pelos trabalhadores.

Anteriormente, nos primórdios do capitalismo industrial, os trabalhadores eram independentes e contratados para desempenharem tarefas. Não havia organização da produção e isso trazia consideráveis problemas, entre os quais podemos citar: desperdício de matériaprima; padrões de qualidade diferentes; tecnologia artesanal; produtividade desigual e horários de trabalhado estabelecidos diferentemente por cada trabalhador para atender as suas próprias necessidades. Diante dessas inconsistências, consequentemente, os níveis de produtividade estavam muito abaixo daqueles aspirados pelo capitalismo significando que o processo precisava ser aprimorado, ser mais eficiente, mais racionalizado.

A partir desse momento os trabalhadores planejavam e controlavam o seu próprio trabalho, passando a ser agrupados em um só local. Desse momento em diante, o planejamento e o controle, já mencionado anteriormente, tendo em vista processos dinâmicos 
de trabalho e eficiência, não são mais controlados pelo trabalhador, mas pela figura do gerente (KUENZER e MACHADO, 1986, apud MELLO, Guiomar Namo de, (Org.). s/d. p.30)

Nesta perspectiva o trabalho passa a ser organizado em todo seu processo produtivo. $\mathrm{Na}$ realidade ele passa a ser fragmentado em inúmeras partes, dividido, onde o trabalhador, para a sua execução, não necessita dominar tecnologias avançadas, pelo contrário, essa fragmentação pouco exigiu do trabalhador, pois com o baixo nível de qualificação que ele possuía era possível desempenhar a sua função. Mesmo dividido, o trabalho é supostamente reorganizado em sua totalidade, pois foram criados mecanismos que asseguraram a sua organização. Então, o trabalho, que passa a ser automatizado e nada interessante, em virtude do empobrecimento do seu conteúdo e da fragmentação, necessita ser controlado externamente para garantir a compatibilidade entre o que foi planejado e o que está sendo executado e, ainda, assegurar a alienação do trabalhador em decorrência do seu próprio trabalho. $\mathrm{O}$ que se pretende com o controle das decisões sobre o trabalho é não possibilitar que as negações geradas pelo próprio capitalismo possam atrapalhar o seu desenvolvimento (KUENZER e MACHADO, 1986, apud MELLO, Guiomar Namo de, (Org.). s/d. p.31-32)

\subsection{A Teoria Geral dos Sistemas}

Embora a teoria proposta por Taylor seja o ponto central, somente a partir da aplicação da Teoria Geral dos Sistemas à organização do trabalho é que a racionalização e o controle com vistas à eficiência, alcançam a sua perfeição. Senão vejamos o que nos traz Kuenzer e Machado no trecho abaixo:

[...] é no âmbito desta teoria que os processos racionais de planejamento, decisão, análise de tarefa, especialização do trabalho e avaliação, vistos como modo de aumentar a eficiência e eficácia do processo pedagógico e sua administração, são percebidos como fundamentais. Desenvolveram-se processos, modelos, instrumentos, tendo em vista a elaboração de diagnósticos, tomadas de decisão sobre os objetivos e meios para atingi-los, o controle da execução, a configuração do grau de obtenção dos propósitos do planejamento, bem como a identificação de desvios e sugestão de medidas realimentadoras. (KUENZER e MACHADO, 1986, apud MELLO, Guiomar Namo de, (Org.). s/d. p.32-33)

No Brasil, esta proposta encontra campo fértil para sua introdução e disseminação. O Estado vivia um momento de exceção, a partir do Golpe Militar de 1964, e mobilizava seus esforços em prol da reorganização do processo produtivo e, posteriormente, de todos os 
demais setores da sociedade. Essa reorganização, entendida como racionalização, assume as feições de dominação de mundo e entremeia todas as relações sociais.

Muitas medidas foram tomadas em função desse novo modelo de desenvolvimento, que se apoiava em novos mecanismos de poder exercidos pelo Estado e também pelo crescente controle financeiro e tecnológico que despontava com o capitalismo internacional. Kuenzer e Machado ilustram claramente as medidas necessárias ao acompanhamento deste novo modelo desenvolvimentista:

[...] os mecanismos de controle tornaram-se cada vez mais centralizados e a participação das massas incorporadas ao processo de produção foram limitadas. A proposta econômica impunha reajustamentos da estrutura de demanda, maior acumulação de recursos para investimentos, definição de projetos rentáveis que complementassem a capacidade produtiva existente e a correção da estrutura de produção. (KUENZER e MACHADO, 1986, apud MELLO, Guiomar Namo de, (Org.). s/d. p.33)

Visando acompanhar esta nova proposta desenvolvimentista, onde a técnica e a tecnologia eram constantemente requeridas para dar sustentação a este novo modelo, procurou-se inovar com as reformas educacionais. A primeira, ocorrida em 1968, tratou da reorganização do Ensino Superior (Lei 5.540/68). A segunda, ocorreu um pouco mais tarde e tratou do Ensino de $1^{\circ}$ e $2^{\circ}$ Graus (Lei 5.692/71). Estas reformas procuraram atingir os requisitos requeridos pelos modelos político e econômico vigentes, pois buscaram ou tentaram buscar a racionalização dos aspectos administrativo e pedagógico.

Embora longo, o trecho abaixo, de Kuenzer e Machado, nos dá a idéia do desafio imposto à educação após as reformas citadas anteriormente:

Nesta época - fim da década de 60 em diante - a referida ineficiência passa a ser combatida com propostas de planejamento educacional, a partir dos estudos dos economistas da educação, tendo em vista o significativo aumento da demanda social, paralelamente à escassez de recursos de toda a natureza. Em resposta ao aumento da demanda, ocorre a expansão e complexificação dos sistemas de ensino, cujo controle passa a ser mais difícil. A educação passa a ser vista como investimento individual e social, em decorrência do que deve vincular-se aos planos globais de desenvolvimento. A expectativa de que a educação atenda às necessidades econômicas, políticas e sociais conduz, inicialmente, à avaliação dessas mesmas necessidades, o controle da execução dos projetos e a posterior verificação do grau de atingimento dos objetivos propostos. (KUENZER e MACHADO, 1986, apud MELLO, Guiomar Namo de, (Org.). s/d. p.34)

Em seguida, Kuenzer e Machado indicam que os problemas e desafios impostos à educação nacional passam a ter uma aliada, ou seja: 
É a tecnologia educacional, suportada pela Teoria Geral dos Sistemas, que oferece a resposta para os problemas assim colocados; ela já havia comprovado sua eficácia nos meios empresariais e na pátria-mãe; bastava, portanto, transpô-la para a educação no Brasil. (KUENZER e MACHADO, 1986, apud MELLO, Guiomar Namo de, (Org.). s/d. p.34)

Até mesmo pelo momento histórico em que se encontrava o país, o Regime Militar imposto pela Revolução de 1964, as proposições expressas por esta teoria são plenamente justificáveis pela ideologia do regime, pois o desenvolvimento com segurança vai exigir o aumento da produtividade do sistema de ensino pela via da racionalização. Se assim está posto, podemos melhor esclarecer através desta citação de Kuenzer e Machado:

[...] a educação é encarada como um instrumento capaz de promover, sem contradição, o desenvolvimento econômico pela qualificação da mão-de-obra, pela redistribuição de renda, pela maximização da produção e ao mesmo tempo o desenvolvimento da "consciência política" indispensável à manutenção do Estado autoritário. Assim, a educação teria efeitos desmobilizadores, impedindo a eclosão dos antagonismos próprios do modelo vigente. (KUENZER e MACHADO, 1986, apud MELLO, Guiomar Namo de, (Org.). s/d. p.34)

Por isto, é possível compreender a instituição de quadros técnicos muito competentes, os quais têm atribuição de preparar decisões que lhes possibilitam alguma independência dos quadros políticos. Com esta possibilidade é possível até mesmo justificar a concentração do poder, que se encontra disfarçada pela neutralidade científica, pelo controle rigoroso, acima do qual se encontram as instancias superiores. Deste modo, é possível afirmar que a tecnologia da educação impulsiona a despolitização da educação, segundo as conveniências da ideologia da Segurança Nacional.

\subsection{A DECEPÇÃO}

De modo geral, podemos afirmar que as propostas de educação geradas a partir desta abordagem foram pautadas em objetivos que tinham por finalidade a solução do problema da educação das massas populares, ou seja, existia uma demanda social que necessitava ser resolvida com a maior eficiência possível.

No entanto, especialistas envolvidos naquelas propostas são unânimes em afirmar que os projetos fracassaram, possivelmente em decorrência de condições impróprias ao seu desenvolvimento ou até mesmo pelas condições de subdesenvolvimento enfrentadas pelo país. 
Esta pedagogia trouxe, a título de inovação, alguns requisitos básicos. Por exemplo, ela propõe a modelização do aluno, em substituição ao que pregava a pedagogia tradicional; a motivação é essencial para despertar o aluno para o novo modelo comportamental que deveria ser assimilado; os objetivos foram fragmentados, taylorizados, possibilitando a saída do aluno de acordo com o seu ritmo.

Segundo Kuenzer e Machado (1986), os meios são fundamentais, inclusive passam a determinar os objetivos. Isto porque o critério de importância é a quantificação, de redução a um modelo; se não atender a estes requisitos não serve como objetivo. Há, então, uma inversão no processo pedagógico, em que as técnicas determinam os fins. Diante disto, o aluno passa a não se relacionar com professor para se relacionar com o recurso tecnológico, ocorrendo uma mudança qualitativa que supõe outra forma de se relacionar com o conhecimento.

Em suma, a qualificação que se dá a uma técnica provavelmente está vinculada à utilização que dela se faz. Se uma proposta é negada ou fracassada, o processo pedagógico deve ser retomado sobre outras bases e isto nos levaria a outra concepção de educação, a novas formas de organização escolar e de um novo processo pedagógico que garanta a inclusão daqueles silenciados pela prática educativa.

\subsection{Referências bibliográficas}

GADOTTI, Moacir. Pensamento Pedagógico Brasileiro. São Paulo : Ática, 1988.

KUENZER e MACHADO, 1986, apud MELLO, Guiomar Namo de, (Org.). s/d.

LIBÂNEO, José Carlos. Democratização da escola pública: a pedagogia histórico-críticosocial dos conteúdos. São Paulo: Loyola, 1990.

MELLO, Guiomar Namo de, (Org), Escola Nova, tecnicismo e Educação Compensatória, São Paulo, Loyola, s/d.

SAVIANI, Dermeval. Escola e Democracia. Campinas: Cortez \& Autores Associados, $4^{\mathrm{a}}$ Ed. 1986. 